\title{
Social Comparisons, Social Support, and Self-perceptions in Group Exercise for People
} with Parkinson's Disease

Tammy L. Sheehy, Meghan H. McDonough \& S. Elizabeth Zauber

Date of submission: October 13, 2016

This is the author's manuscript of the article published in final edited form as:

Sheehy, T. L., McDonough, M. H., \& Zauber, S. E. (2017). Social Comparisons, Social Support, and SelfPerceptions in Group Exercise for People With Parkinson's Disease. Journal of Applied Sport Psychology, 29(3), 285-303. https://doi.org/10.1080/10413200.2016.1266711 


\begin{abstract}
People with Parkinson's disease (PD) may experience declining function, and limited interaction with others with PD. Group exercise provides opportunitites for physical accomplishment and social support, as well as potential social challenges. We used interpretative phenomenological analysis to examine experiences of social comparison, social support, and self-perceptions of 20 people with PD in group exercise. Participants experienced: (1) reticence evolving to inspiration; (2) anxiety relief through camaraderie and breaking taboos; and (3) maintaining athletic identity through participating and helping others. Practical implications include facilitating a safe space and support to alleviate anxiety and sustain participation.
\end{abstract}

\title{
Keywords
}

coping, social identity, interpretative phenomenological analysis 
Social Comparisons, Social Support, and Self-perceptions in Group Exercise for People with Parkinson’s Disease

Parkinson's disease (PD) is a progressive, neurodegenerative illness that leads to severe disability. Symptoms include tremor, bradykinesia (slowed movement), rigidity, postural instability, depression, pain, sleep disorders, and reduced quality of life (Jankovic, 2008). There is no cure for PD; therefore, treatments are aimed at alleviating symptoms and sustaining quality of life. Pharmaceutical treatments can temporarily allieviate some symptoms, but do not slow disease progression, and are associated with significant side effects (Kalia \& Lang, 2015). Therefore, people with PD typically experience increased immobility, isolation, and dependence on others as the disease progresses (Chrischilles, Rubenstein, Voelker, Wallace, \& Rodnitzky, 1998). Exercise reduces the severity of some symptoms and improves quality of life, so is a promising adjunct treatment (Alberts, Linder, Penko, Lowe, \& Phillips, 2011; Ridgel, Peacock, Fickes, \& Kim, 2012). Group physical activity programs for people with PD are emerging, and such programs have been shown to improve social support and quality of life (Combs et al., 2013; Hackney \& Earhart, 2009).

People with PD may face unique challenges in the group exercise context because of the degenerative effect of PD on motor ability. Many studies have cited participants with PD feeling betrayed and embarrassed by their body’s uncontrollable, involuntary movements and associated feelings of loss of physical control (e.g., Posen, Moore, Sadeh Tassa, Ginzburg, Drory, \& Giladi, 2001; Sunvisson, 2003). Given the physical control of the body expected within an exercise environment, participation in certain exercise-related activities may be challenging for those with PD. However, group exercise environments have potential to improve physical self-perceptions through bodily experiences. Exercise reduces physical symptoms and improves self-efficacy and physical function in people with PD (Combs et al., 2013; Ridgel et al., 2012). Many people with PD are aware of these effects, and the belief 
that exercise may help with coping through minimizing symptoms and slowing disease progression is a common motive for exercising (O’Brien, Dodd, and Bilney, 2008). In group exercise interventions using dance, people with PD increased balance confidence (Hackney \& Earhart, 2010) and felt more competent and independent in activities of daily living and mobility after participating (Heiberger et al., 2011). Furthermore, people with PD in a group walking program reported an increased sense of physical capability, endurance, and confidence to overcome symptoms (Sunvisson \& Eckman, 2001). Additionally, exercise may be used as a coping resource in ways other than improving motor symptomology or perceptions of disease progression. For those with an incurable illness such as PD, participating in group exercise may provide an opportunity to creatively cope with the disease by rejecting and redefining stereotypes (Haslam et al., 2009) and challenging assumptions of poor physical function by publicly demonstrating their ability to complete intense workouts, a highly valued trait in society.

People with PD also face potential social challenges in a group exercise environment as interacting with those with more advanced symptoms may be a source of stress that may affect social interaction, social support and social comparison processes. People with PD often refrain from participation in support groups for fear of seeing those at more advanced stages of the disease and being reminded of their inevitable disease progression (Charleton \& Barrow, 2002). Some of those who do participate in support groups make self-enhancing comparisons to other group members who they perceive as worse off by reflecting on their own 'good fortune' for being in a less severe stage of the disease (Charleton \& Barrow, 2002). These experiences are consistent with social identity theory, which posits that people will associate with or distance themselves from others in order to enhance self-concept (Bruner, Dunlop, \& Beauchamp, 2014). Upward comparison involves identifying with a person or group who is seen as being better off, and downward comparison is relating to 
someone perceived as worse off (Festinger, 1954). Both upward and downward comparisons can involve affiliation, in which one sees oneself as similar to the person with whom one is identifying, or dissociation, in which one perceives oneself as different than the comparison person (Taylor \& Lobel, 1989). Social comparison can be reframed to improve self-concept (Festinger, 1954), but also depends upon the likelihood of reaching the comparison person's level in the future (Buunk, Collins, Taylor, VanYperen, \& Dakof, 1990). For individuals with PD, it can be difficult to adopt self-enhancing comparisons because many symptoms are publicly visible, generally perceived as negative, and known to be inescapable (Tajfel \& Turner, 1979). However, when relationships within the group are secure, group members are more likely to find novel solutions to group problems and self-enhancement (Tajfel \& Turner, 1979).

While some people may focus on differences between themselves and others within a supportive group environment, other research examining women with PD in a supportive group environment elucidated that affiliation to a peer group with similar disease experiences relieved the feelings of alienation that many felt through being a minority and vulnerable to stigmatization in society (Posen et al., 2001). Rather than differing and distancing oneself from others within this group, these women focused on their similarities and shared experiences as ways to feel like they are not alone and not different to others. Coping in this sense was enhanced through the provision and acceptance of emotional support (Posen et al., 2001). Satisfaction with social support is associated with less psychological distress for those with PD (Simpson, Haines, Lekwuwa, Wardle, \& Crawford, 2006), so opportunities to build support networks may be important. Research on social interactions and support in group exercise among those with PD is in its early stages, but one study showed a tango dancing intervention led to improved social support compared to no intervention (Hackney \& Earhart, 2009). Given the varied potential social experiences within the group exercise context among 
people with PD, further examination of people with PD's lived experiences, challenges, and social interaction and support in the group exercise environment is needed.

Participating in group exercise may be adaptive for people with PD as it may provide opportunities to overcome physical challenges and receive social support. However, little is known about people with PD’s interpretations of their social experiences and physical challenges in a group exercise environment, and how those lived experiences may affect their motivation to participate, and perceptions of benefits they may derive from participating. Participants know that PD leads to physical declines, but they may also expect that exercise may slow this loss of function. These expectations, coupled with the opportunity for support from others who understand the disease, while being faced with the potential challenges of interacting with those at a more advanced stage of PD, may affect lived experiences in the group exercise context. Therefore, the purpose of this research was to examine people with PD’s lived experience of social interactions, social support, social comparison, and physical challenges in a group exercise program. Research questions included (1) what are participants' perceptions of their social relationships, social comparisons, and experiences of social support with other people in the program? (2) what are participants' understandings of their physical competence in the exercise program? And (3) what outcomes do participants experience as a result of participating in the program?

\section{Method}

\section{Interpretative Phenomenological Analysis Methodology}

Experiences with social processes and self-perceptions in physical activity among those experiencing PD are contextual and embodied so we chose interpretative phenomenological analysis (IPA) to guide this study. IPA is a qualitative methodology developed in health psychology to investigate how people make sense of major life experiences (Smith, Flowers, \& Larkin, 2009). IPA is interpretative, and doubly hermeneutic, 
in that it involves interpretating the explicit meaning of participants' words within their context, and incorporates the researcher's interpretations based on examinations across participants and in light of theory and disciplinary knowledge (Larkin, Watts, \& Clifton, 2006). IPA is phenomenological in that it takes the view that people understand their experiences in relation to their context, bodies, and relationships. IPA is also idiographic in that it is concerned with the individual experiences of people within particular experiences or contexts. The experiences of each participant are analyzed in depth to learn about their individual experiences and interpretations prior to looking across cases and in engaging in interpretation in light of theory and empirical and practical knowledge. IPA allows for some degree of flexibility in ontological and epistemological approaches. In this study we took a contextualist perspective consistent with Larkin et al. (2006) which takes the ontological stance that while things exist and are real in the absence of humans, this reality is meaningful in the context of human life and our interpretations of it. Epistemologically, we can learn about people in their context through examining how they have understood their experiences. IPA uses small, purposively-selected samples and primarily inductive analysis (Smith, 2004). IPA is concerned with the meaning individuals ascribe to their experiences, and takes a symbolic-interactionism perspective, which assumes that the the meaning an individual ascribes to the events in their lives is the central concern, and that this meaning is accessible through interpretive processes involving both the participant and the researcher (Smith et al., 2009). Because IPA is well suited to examine the physical and social context in meaning making it was thought to be suitable for examining experiences in physical activity contexts among those coping with PD.

\section{Group Exercise Program}

Participants were recruited from a non-contact boxing-based group exercise program for people with PD in a large Midwestern city in the United States. Boxing is discussed 
within the program as a metaphor for taking constructive action against the disease. Four levels of classes are offered: Level 1 is designed for those with a high level of functioning, and level 4 is for those who require one-on-one caregiver assistance. Each 90-minute class includes a variety of anaerobic, resistance, and flexibility exercises based on boxing training (e.g., speed bag work, rope jumping). Classes use an interval training format.

\section{Participants}

Twenty people with PD (8 males, 12 females) who were currently participating ( $n=$ 18) or had participated within the last 12 months $(n=2)$ were recruited for this study. Mean age was $65.6(S D=6.47)$ years and mean BMI was $27.70 \mathrm{~kg} / \mathrm{m}^{2}$. All were Caucasian, 17 were living with a partner, 17 had completed postsecondary education, 11 were employed, and median household income was $\$ 80,000-\$ 100,000$. Participants were diagnosed 1-36 years prior to the study $(M=8.75, S D=7.94)$, all took medication to control PD symptoms, and they had attended the program for an average of 4.15 years $(S D=2.06)$.

\section{Procedures}

The study was approved by the university institutional review board. Prior to recruitment, the first and second authors visited the program several times to familiarize themselves with the program and build rapport with the trainers and participants. The third author is a neurologist and a member of the program's advisory board on a voluntary basis, and has an established rapport with the program staff and many of the participants. The third author introduced the other authors to the program staff and provided expertise in conceptualizing the project, interpreting the findings, and writing the manuscript, but did not participate in data collection or direct analysis of the data to avoid being in the position of having a dual relationship with the program or the participants.

The trainers distributed a recruitment letter describing the study purpose and contact information to the approximately 130 people on their membership email list. The sample size 
was limited to a maximum of 20 to include enough participants to document commonalities and variation in experiences in the program, and to be small enough to allow sufficient resources for the time-intensive IPA analysis (Smith et al., 2009). IPA is often conducted with samples smaller than in the present study, but the method is flexible and has been adapted to larger designs as needed to address the research question (Clare, 2002; Smith et al., 2009). Twenty-nine responses were received, and the first 20 participants who met the study criteria were interviewed. In-depth interviews were conducted by the first author $(n=$ 16) and a graduate student research assistant $(n=4)$ who both had extensive training from the second author in interviewing techniques, and prior experience conducting interviews and conducting qualitative analysis. While there are advantages to having one person conduct all interviews and analyses, we included a second interviewer to improve feasibility of the project. Most PD medications provide a reltively short window during which participants’ motor symptoms are reduced enough to ease physical activity and speaking. So participants typically time their medication to coincide with class participation, and most participants were only comfortable, or able, to participate in an interview while they were on their medication. Therefore, one researcher could only interview two people in a given trip (one before and one after the program session). Given that the program was not in the same city as the investigators, we decided to include a second interviewer so up to four interviews could be conducted on each trip.

Interviews were conducted in a quiet, private room at the program's gym, a public library, or the university. At the first interview, participants completed a consent form and demographic questionnaire. Interviews were audio recorded and lasted 40-90 minutes. A semi-structured interview guide was developed based on IPA guidelines (Smith et al., 2009) and included introductory questions to further build rapport, followed by the main questions regarding social relationships and support (e.g., What are your relationships with the other 
participants like?), physical competence (e.g., How do you feel about your ability to do the exercises?), challenges or difficulties with participation (e.g., Do you experience any challenges or difficulties with participation? If so, can you describe those challenges?), and changes they experienced as a result of the program (e.g., Can you describe any changes you have experienced in your life as a result of being in the program?) and a series of follow-up questions for each main question (e.g., following the social relationships and support main question, participants were asked about their perceptions of acceptance, belonging, friendships, social support, how those social experiences were similar and unique from other relationships in their lives, how important they were, etc.). Because IPA is concerned with how participants interpret their experiences, the order of the questions was flexible based on the direction of the discussion taken by the participants, and participants were asked to respond to the questions, but also to contemplate and discuss elements that they felt were relevant to their experiences, and how they made meaning of their experiences in the program. A copy of the complete interview guide is available from the authors upon request.

\section{Data Analyses}

Audio recordings were transcribed verbatim and names were replaced with pseudonyms. NVivo 10 (QSR International, 2012) was used for data management. Analysis followed IPA procedures (Smith et al., 2009). We first examined each case individually to adhere the idiographic perspective of IPA (Smith, 2004). For each participant, the first author read the transcipt to gain a holistic view. For those participants whose interviews were conducted by the research assistant, the research assistant and first author discussed the participants' attitudes and dispositions and the research assistant's memos. The first author then conducted a line-by-line inductive analysis to code the participant's claims, concerns, and understandings pertaining to the research questions (Smith et al., 2009). Similar codes were grouped into categories. Memos were used to record and set aside researcher 
interpretations for later stages in the analysis, and ideas for follow-up questions for the second interview. This idiographic process was repeated for each participant. The coding was reviewed by the second author, and the first and second author discussed the coding and possible alternate points of view. We also compared the theme labels and descriptions to existing conceptualizations of social comparison (e.g., Festinger, 1954) and social support (e.g., Richman, Rosenfeld, \& Hardy, 1993), and where the meaning was substantively similar, adjusted theme labels to be consistent with the nomenclatures used in the existing literature. While this procedure is somewhat deductive, it was applied in a limited fashion to avoid unnecessary proliferation of terminology. In cases where disagreement arose, both authors reviewed the relevant data and a decision was reached by consensus discussion. The first author then re-read the transcripts to ensure consistent coding. A table of themes was created for each participant and a summary of each participant’s experience was written (Larkin et al., 2006).

Follow-up interviews were conducted by phone $(n=17)$ or in person at the program gym $(n=2)$ with all but one participant, who we were unable to contact. That participant's data was retained in the analysis. Participants were given a copy of a summary of findings that pertained to them, were asked to expound upon how well that description represented their experiences, and were asked any follow-up questions that arose during analysis. These interviews were transcribed and incorporated into the analysis.

Each participant's transcripts, table of themes, and summary, along with memos taken throughout the analysis were reviewed, and a second stage of analysis began focused on comparing experiences across cases and considering interpretations in light of theory. Similar experiences were interpreted as themes and a description of these themes, incorporating data extracts, was written (Larkin et al., 2006). The second author reviewed the theme descriptions, and the results were again discussed with the first author, with differing points 
of view resolved through consensus. The third author then read these descriptions and provided input.

\section{Results}

The discussions with the participants, analysis of each person's story, and consideration of the shared and unique experiences with the group exercise program resulted in three themes. The themes related to (1) an initial reticence to being involved that evoled into being inspired by other participants as they experienced support and accomplishment; (2) finding relief from anxiety and depression through the camaraderie, positive spirit, and breaking taboos about PD; and (3) finding ways to maintain identity as an athlete and physically capable person through physical accomplishment and the opportunity to help others at more progressed stages of the disease. Woven through all three themes was the finding that all participants in the study articulated a desire to join the program in order to manage and reduce physical symptoms, and all found considerable value in the physical accomplishments and camaraderie and support provided by fellow participants.

\section{Reticence Evolving to Inspiration}

Exercising control: Everyone who participated in the study spoke of being drawn to the program in hopes of controling PD symptoms through exercise, and a hope that exercise would slow the progression of the disease. Participants were well aware of research suggesting exercise can improve symptoms and quality of life, which provided hope and potential for control:

I hadn’t exercised intentionally for years. So I just felt that I would have a real opportunity to take better care of myself and perhaps delay the onset of the disease. I don't believe you reverse [PD]. I do believe that you can definitely slow the progress and it feels like reversal because you're getting in condition. If you haven’t been in shape and you're working out, you just feel better. And the endorphins and everything 
that affect your emotions that go with it are there to kind of bolster that feeling of well-being. (Lance)

“I feel less symptomatic. I mean, I feel, I feel less like a person with Parkinson’s, I feel more like a normal person” (Percy). This opportunity to minimize symptoms provided an opportunity for physical relief, relief of embarrassment about being negatively evaluated, and relief of fear of detection, as many spoke of the struggle to keep their PD diagnosis a secret because information about their diagnoses may cause harm on the job, for example:

I was concerned that if my employer found out...if there was a perception that I was a weak link or there was a perception that, um, what I was doing wasn’t valid...that I could screw things up because I was having a bad day. (Hayden).

Reflections of a future self: Joining the program was not easy though. Many participants struggled with anxiety about seeing others at more advanced stages of PD, which led to identifying with those participants, and seeing a reflection of their possible future selves:

The very first class I went to, I cried, because I, I can see a lot of people and how they had, in a sense, deteriorated, you know, and I thought, that's gonna be me. So it was really hard, the very first class. (Olive)

I don't know that it gets in the way of my participation but I, I think that coming on Saturdays especially, when you see [people in classes for] all the levels, some of those people have been in [the program] pretty consistently for the last several years and they still degenerated. They still are eventually gonna lose to the disease. I think that I’m pretty emotionally stable and I think that I'm dealing with that pretty well, but I'm not where they are yet. So I think in the back of my mind I'm thinking, will I be able to come do this when I'm where they are, with a spouse who may be leading 
them in by the arm or pushing them in a wheelchair, or driving them here? And a lot of those questions remain to be answered. (Lance)

The apprehension surrounding seeing others who are at a more advanced stage of the disease, and identifying one’s future self with is an example of a downward affiliation comparison, and was experienced as disconcerting and overwhelming at first. But, as participants gained more experience with the program, many described noticing how they were sometimes doing well compared to other participants whose symptoms were worse, particularly in the challenging boxing classes where it was clearly visible what others could and could not do:

I'm pretty blessed that my Parkinson's is, is not as progressed as most people. Probably some of the folks [in the program], you know, have other challenges of, you know, getting up in the ring, or stepping over things. But I'm, I can jump rope, I can run..., I can do push-ups, sit-ups. (Hayden).

I hadn't jumped rope for a long time, so I, when I first started jump roping at [the program], I could only go round maybe once or twice. And now, I'm probably one of the, I can do it the longest of most people. (Gail)

A shift like this to a downward dissociation comparison was experienced as noticeably more positive - feeling blessed, and the best at some tasks. While these comparisons are favourable and boosted confidence and motivation to keep exercising, identifying others as worse off led to participants having mixed feelings about these thoughts, feeling both affirmed and selfish. Notably, these mixed feelings are evidenced both in participants' descriptions of their feelings, and in the apologetic tone adopted in admitting feeling good about comparing favorably: "Sometimes it's encouraging to me because, this is probably gonna sound selfish or something, but I'm still able to do more than a lot of the other people in the class and so that makes me feel good” (Esther). 
They're in the same boat that I am. And you see that you're, some people are so much worse off than you are. And you should not feel so [sighs], uh, you shouldn't feel bad. And it makes you feel, in some ways it makes you feel better and some ways it makes you feel worse because you see, what could, you could be down the road. Otherwise you're thankful, I mean, I have to be honest, that you're not as bad as they are. And I, that makes you work a little bit harder I think, so you won't be that, in that boat.

Physical competence: As participants attended more exercise sessions, they began to improve, in some cases beyond what they were capable of before being diagnosed with PD. “It proves that I can do something like that, and I never would've, I worked out all my, well, most of my life and this is the hardest workout I've ever done, but I can do it every time” (Gail). This improved confidence, and proof to others of the ability to do daily activities was a great source of pride and autonomy:

I no longer ask my children to come over and do for me, uh, I do all my chores around the house, I do all my yard work and everything. I don't have my boys comin' over to cut my grass. If there is, uh, home repairs, I do 'em. I work on my cars...It's given me back a lot of, uh, pride and a lot of ownership of, of who I am. (Hayden)

The presence of multiple levels of classes provided accessible programming to people of all levels of fitness, boxing skills, and PD symptoms. But also created a visible and valued way to measure physical competence that could be both rewarding, and anxiety provoking. Over time, some participants improved and moved up to a more challenging class: "I got into...a class that was the hardest, um, not as far along in their, in their diagnosis. So it helped give me a little bit more encouragement” (Olive). But for people with PD, the possibility of 
moving classes would also mark declining abilities someday: "The thing that I'm concerned about is the day they tell me I'm a [level] two. I think that'll be really hard” (Lance).

Support from those who have been there. As participants spent time at the program, everyone discussed coming to feel understood by others with PD. Many people spoke of feeling more comfortable being themselves, and this comfort helped them open up about PD in the program context:

Just almost from day one, you know, everybody’s just so nice. And you can come to [the program] and it, everybody, even though you have different symptoms, a lot of people have different symptoms, but some of them are similar. They know how you feel, and you can be yourself there. (Gail)

Many spoke about this support as being unique from what people without PD were able to provide because of the shared lived experience with PD. “Here, I'm with people that are in the same boat that I'm in" (Hayden). As Cliff shared:

Physical [benefits] was one reason [for joining]. But it was also really delightful to have this group of acquaintances who we could talk with each other about Parkinson's and about medication and about the things that we experience. Some of those things are even harder to describe to people who don’t have Parkinson’s. So it was very, very meaningful, socially, to come to [the program] and be a part of that group and get to know people. Very socially important. Now I really felt support at [the program] with, with the fellow boxers who had Parkinson's...I had been very secretive about having Parkinson's, and coming in here, it was all open, it was all on the table. And that was a nice change, that we could talk about it openly. I could see other people, I could evaluate their condition, their status. I could see people worse than me, I could see people better than me. A real, real learning experience. Very informative. So I had access to information that outside of [the program] I didn't have 
access too...The support...has a little, little different quality to it because of fellow travelers. I think it’s even more, more impor'nt than the support that I get from my wife...I don’t think she really understands the way they understand.”

The support from the trainers, who did not have PD but who worked full-time with those who do, was seen as extraordinary in terms of understanding the specific needs and challenges for people with PD, and being empathetic: “I don’t know how someone can understand how a Parkinson's person feels without having it as much as [the trainers] do...They come as close to being empathetic, they're not sympathetic, they're empathetic” (Norah).

Shifting comparisons. As participants got to know each other better, many shifted the reference point for comparisons with those who had more progressed symptoms. Instead of seeing a reflection of their own eventual decline, participants became inspired by witnessing their teammates who had more advanced symptoms become role models and examples of coping and succeeding, even with PD:

I was kinda, kinda excited about it. I mean, I remember coming, everybody just kinda welcomes you. They made you feel like, you know, this could be a place you could belong. But you see people at all different levels. You saw, uh, people with, uh, all different challenges. I will tell you that, when I first started coming, it scared me because I was seeing people that had had the disease longer than I was having. And your mind just starts to go, well, is that gonna be me in a year? Two years? Five years? You know, cause you get, you really do get an exposure to folks, and not necessarily folks that are old, you know. We’ve got people here that, that got Parkinson's in their forties and are not even in their fifties...So it scared me. But on the other side of the coin, it encouraged me as time went on because I, I saw that they were dealing with it. I saw that they were overcoming it. (Hayden) 
[Rob] can’t do everything that all of us do because he's, sometimes he's symptomatic...He freezes and, so sometimes he struggles to get up to the bag, but...When he gets there it just blows me away, cause I'm thinking, how can he do that when he just struggled to get up to the bag? (Lance).

In many cases, the same people who were initially viewed as worse off in either downward affilitation or dissociation comparisons became role models with whom participants could upwardly affiliate and aspire to emulate as they shifted from comparing based on PD symptom severity to comparing physical fitness, skill, and coping ability. This shift helped participants see each other in a new light, and gave hope for the future:

When I first started going to class I was sorta depressed. 'Cause I saw sorta how, well you see these people come in behind ya, where you're going. And then when you talk to other people then, that have been doin' this, like, [Patricia], for thirteen years and she’s in my class and they're doing better than me, much better than me. Uh, she doesn't walk as well as me, she doesn't talk as well as me, but she’s exercising better than me. So I think, we'll see, you know. There's a good possibility that thirteen years from now I might be where I am. (Belle)

This support encouraged participants to attend and persevere in overcoming physical challenges, which led to the pursuit of new possibilities:

I said I’ve never jumped rope in my, you know, sixty years of living. I can’t jump rope...Well, I saw people that were worse off than I, and I thought, well, maybe I can. So, I learned to jump rope. It's that kind of, yes, you can do it. You may not be able to jump rope as well as so and so or such and such, but you can do it... It's a very empowering feeling. (Renee)

Comfort in a safe, supportive space. Participants also valued the support they got from each other, support that ranged from the practical: "Everyone helps everyone put, like, 
gloves on. Ah, some of them will help me, when I try to get in the ring, they'll hold the ropes up, you know, just things like that” (Belle), to the emotional: "When they hug you, you really feel like they love you and they care about you” (Lance). For some, the hope, pride, and confidence gained from the program helped them focus on making the most of good days and controllable factors: "When I'm on the good days, it's like I was never ill...My approach is to make as much outta, make as much as I can out of what's there and not get all upset about off days” (Toby). For some participants, this newfound comfort was specific to the safe program space, as they continued to fear evaluation and attempted to hide their symptoms elsewhere: “I make sure my medicine’s adjusted so my symptoms are not showing prominently. I try to conceal my symptoms.” But in the program, “I’m just more willing to acknowledge that I have Parkinson's, more willing to answer questions about it, talk about it. More open, um, comfortable being open about it, whereas before, I was not” (Cliff).

\section{Anxiety Relief through Camaraderie and Breaking Taboos}

The participants in the second theme found a safe space and cameraderie in the program to share humor and challenge taboos about PD, illness, and disability as a way to have fun, forge supportive relationships, and which helped them cope with anxiety.

Overwhelmed. A focal idea was that many participants were experiencing considerable anxiety, depression, and/or stress related to PD, and, for many, about joining the program. Like all participants, exercising control, being drawn to participate in the program due to a desire to reduce their physical symptoms and potentially slow progression of PD through exercise was an important impetus for joining. A strong part of that desire to control PD symptoms through exercise was related to reducing anxiety about the disease:

Fiona: I can't talk about it without crying, so, um, I'm getting real upset. It's just not fully accepting. I think one of the things I do is have a lotta things going on in my life to prove I don’t have it. And then I get tired...I think I just purposely assign myself 
too many things to do to prove that I'm like I was before I was diagnosed with it. So that's, that's basically it. It's no fun [laughs]...

Interviewer: What reasons did you have for joining [the program]?

Fiona: I wanted to do everything I could to delay, I think, keep active and delay if, if possible any progression.

Many were also apprehensive about meeting others with PD, going to an unfamiliar place, and their physical ability to do the training:

I came and checked it out one evening when the coaches weren't here and I thought, [quick inhale], I could never do that. They were like crazed people...Like, I had all those kind of fears. Well, you know, what if it's like one of those classes you go into and the person at the front is saying, no pain, no gain, and you hurt yourself and then you can't do anything? ... Once I was assessed and felt reassured this was gonna be a good thing, it was. (Imelda)

When participants overcame their initial reservations and gave it a try, for the most part, their concerns were not realized, and, in common with all participants in the study, took pride in their improved physical competence: "I’m just not real athletic and it has helped me get a little more, realize that my body can move pretty much more than I figured it could, or ever would've thought I can move it” (Silvia).

I started out barely knowing how to jump rope. And now I, you know I started out only being able to jump on one foot. So right foot, right foot, left foot, left foot. Now I can jump rope both feet and I can go forwards and backwards. I couldn’t even know, you know, how they criss-cross or whatever. I never even, I never even seen that. Now I'm like, I'm gonna go figure that out. And, um hula hoop...I want to know how to do that...I carry the, I wanna say, philosophy, if I can do it [at the program], I can do it wherever I want to. (Imelda) 
Some concerns about physical challenges were not dispelled, but as the participants gained experience they learned how to cope and became more comfortable making modifications to enable participation. For example, Norah preferred to stay in a lower level class despite encouragement to move up as she gained experience so she would feel more comfortable about her physical abilities relative to the other participants: "Those guys can really jump rope and they, I wasn’t comfortable. I wanted to not stand out as being the, always last.” Participants’ increasing comfort with the program was also evident in the shift in tone from one of apprehension about the intensity and expertise of other participants to one of feeling secure enough to "figure it out."

Cameraderie. The hallmark of this theme was in how the common experiences with PD and interactions in the safe space created by the program provided the opportunity to share jokes and have fun together. Like all participants, the support from those who have been there was unexpected, and unique. In this theme, a valued and unique feature of that support was that their teammates had the ability to be upbeat and enjoy life despite the challenges of PD. The freedom to be spirited, positive, and not focus on the disease was refreshing and provided an outlet to cope.

I'm a timid person anyways. Not when I'm alone, but in a group. Then put a group of Parkinson's people together, come and watch us, it's yak, yak, yak, yak, yak...I had to find something, some place where my physical, lack of physical abilities didn’t count for anything, 'cause everyobody else had them too... When I see these people, other people in my class, how they don't let it, it get them down. They still makes jokes, and there's a love, really, in the class. But we set funny music playing, [Matt] comes in, telling jokes. It's uplifting...I look at [Matt] and he’s always so up, he’s so funny, he sings songs, he dances, he’s like a big teenager...I know that he isn't off very well, and his hands shake and yet he can still be so up. He’s an inspiration to me. (Norah) 
Breaking taboos. Participants found inspiration and stress relief from being around others who diffused tensions through shared humor about PD symptoms and medication side effects that would be taboo and uncomfortable outside of a supportive group of people who shared the same diagnosis: “I joke and facetiously tell people that I’ve ruled out a second career in Swiss watch repair or hand grenade construction. But I do realize there are more limitations on what, you know, I, fine motor skills that I can do and that kinda irritates me ‘cause I’ve always been a hands on kinda person.” (Renee). Ingrid explained:

$[\mathrm{M}] \mathrm{y}$ nickname is Vegas and the reason for that is I love to dance while I'm working out. So I'll be boxing like, oh, like this [does punching movement], and music will come on and I'll start doin' this [shaking hips from side to side], and it's gotten to be such a joke...Somebody said to me, "Do you really like to dance? Or is that a way to hide dyskinesia?” And I said, "Maybe both.” [coughs] Excuse me, but this is really the only [laughs] place I act that crazy. I mean, I'll dance through the gym and grab people and say, “Come on, let’s dance,” and it’s just fun. You know, I think it says something about all of us being in the same boat. Like, I don't feel like any of 'em are going, “She’s got Parkinson’s. Something weird with her.” It’s like, everybody’s like, “Boy, you have energy!” And I’m like, “Yeah!”

Humor was a way to both have fun and alleviate anxiety about PD, often in ways that may make other people unconfortable, or which other people in their lives may shy away from for fear of making them uncomfortable. Breaking taboos together alleviated anxiety about the disease, but also cemented their shared connection:

These people have the same thing I do. We have the same thing in common. And I look at, even if it's a judge, I feel like I'm equal to him because we all act like that to, to each other. It's just something that, nobody makes fun of. And we all make jokes, 
say a joke or whatever. But, you know, it fits. You feel like you're equal to everybody. (Dawn)

The humor was also fun, encouraging, and fostered belonging: "Those are things that really, um, give a person a sense of belonging and encouragement to go on to make an effort to accomplish something new” (Fiona).

\section{Maintaining Athletic Identity through Participating and Helping Others}

Atheltic identity. For participants who had been physically active most of their lives, joining the program was about exercising control, as it was for participants in the other two themes, but it was also about maintaining a sense of athletic identity:

Kyle: I’ve got kind of an addictive personality in mostly a positive sense, I think. Like the running thing. I got hooked on running years ago...Like I've gotten addicted to [the program]...But, like I say, the running, that's been a tough thing for me to kinda give up the running... Some of the guys I used to run with, we still walk at least once a week. Things like that have not changed.

Interviewer: Why did you decide to join [the program]?

Kyle: I'd seen a couple articles in the paper and was just kinda fascinated by it. I was still running pretty regularly so I was getting good exercise, so I felt like I was, you know, I knew I wanted to stay active and stay physically fit and I was doing that pretty well...[But] I wasn’t able to run the distances that I was used to. I was kinda fascinated by the boxing thing...The physical part was really all I was thinking about. Participants in this group were accustomed to feeling physically competent, and found the physical limitations of PD threatening to their identity as an athlete, exerciser, or as physically capable:

I didn’t let my family know for a while. My kids, I mean. My wife knew, we share everything. Didn’t let me brother and sister know for a while. You know, I just 
thought I’d keep it under wraps. 'Cause, I didn’t really, for the most part, I was slowing down pretty bad, and, I gained a lotta weight. I had started to become a couch potato. (Hayden)

The opportunity to use exercise to cope with PD was comfortable and familiar: "I was always an athletic lady and I always did athletics things and stuff like that and, I just had to have something to do and something to keep me going” (Dawn). Like in the other themes, downward dissociation helped to put challenges in context, and to see participating as feasible: "I saw people that were further advanced than I was doing it and I thought, well, if they can do it, I can do it” (Albert). Like all of the participants in this study, participants experienced improved physical competence, which they valued highly. But particularly for this group, who had a long history of valuing physical competence, improving or at least maintaining physical ability was a concern: “I don’t want the day to come when I can’t. That bothers me because I want to be able to keep strong with what I think is making me stay strong. And the exercise is, oh dear [laughs], yes, it’s tough.” (Jackie). Many participants also relished the opportunity for competition and pushing themselves physically: “I'll do it and I'll stay there until it's over with, if it kills me. If there's somebody else there, I, like I say, I have this competitive spirit [laughs]. And there’s, no body is gonna beat me” (Dawn).

Support through supporting others. But once participants became involved in the program, as was discussed in the first two themes, they also came to appreciate support from those who had been there and who were coping with similar challenges: "It's good to find a group of people that are dealing with the same thing...they're not ready to throw in the towel...Everybody is, without fail, friendly, accepting, “how you doin’?” You know, willing to listen to you” (Kyle). Receiving this support imparted a desire to give back. The program provided participants with an opportunity to use their skills in physical activity to serve other group members by assisting in other classes: 
It's not just a workout, you know. Not only do you come here, I mean, I guess you could come here and just do the work out and leave. But we all have, see folks at different levels that are, can do more than I can do, that can do less than I can do. And sometimes they need challenges. So even though I'm here to, for myself, I feel like I also can give back to other folks that are here. So it gives me a chance to serve other folks as they're handling it instead of just always taking. (Hayden)

“I just kinda take it upon my, you know, if I see somebody not doin’ what they, you know, need to be doin’ or goin’ in the wrong direction, I, I just feel like I should help out” (Albert). Assisting participants in the lower functioning classes was a particularly valued way to give back because of the opportunity to help people at a later stage of the disease succeed, to be inspired by witnessing other participants' accomplishments, and grow in their own athletic identity by taking on roles such as coach or helper:

The four level, I volunteer at that one...that's been a tremendous gift to me. I've just been doing it for, maybe the last six weeks or so. One of the other guys that I work out with was doing it, and he was telling me that, how much he was enjoying it. And I, that's when I got the idea that I would start coming. So it's been an eye opener to me about the disease because I, you know, most of the time I'd been just coming to the PD1 class and those are the folks that, you know, that I was seeing. But the, at the four level, the, the symptoms are much more significant in terms of mobility. It's diff-difficult for a lot of people to stand, for example. And get, get up out of a chair. And so that's been, you know, helping with activities and making sure they're maintaining their balance and so on. Everybody's been so pleasant, you know, and saying thank you and things like that. Where I, I mean, it's the same feeling you have in the other classes, I guess, is what I'm trying to get at, the, the attitude. So it's, it's given me a little 
bit, I think, of a feeling that the coaches get when they help. That's been good. So it’s, it’s increased my experience at [the program],..I just hadn't really figured out that it was some'in that I could do. And the coaches have been good and they have a training for the trainers program....and I'm signed up. I'm gonna do that next month, the two and a half day course. 'Cause I think it'll help me with volunteering. (Kyle)

More comfortable with PD. Often, fears of being evaluated were reduced as participants felt their symptoms improve and they realized that having PD did not prevent them from succeeding: "I went from, kind of in bad shape. No, I was in bad shape. I was trembling. I had a lot of days where I felt awful...And now you don't know that I have Parkinson's” (Jackie). Many participants felt more comfortable with their PD and telling others about their diagnosis:

Interviewer: Has participating in [the program] had any effect on your relationships with other people in your life?

Hayden: Yeah, it’s made things closer. 'Cause like I said, I was pulling away. I just started to become a recluse. I went to work 'cause I had to, I went to work to make money. I was hiding behind Parkinson's. Doing everything I could to hide it...I can now, I feel I can open up to people, you know? I came to grips with it. I’ve got Parkinson's, it doesn't have me. So I’ve kinda got over myself, you know. There was a lot of pride and a lot of, like I say, a lot of mourning of what coulda-should been. And I'm doing what I need to do to enjoy what I can.

\section{Discussion}

This study examined experiences in a group exercise program for people with PD. While similar questions have been examined in other group exercise contexts and clinical populations, these findings highlight the particular challenges and social and emotional 
processes encountered for participants who share a diagnosis of a degenerative, incurable illness that profoundly affects motor abilities. While all participants began the program with the hope that exercise would improve their symptoms and slow disease progression, many experienced anxiety about seeing people at later stages of PD because they found it difficult to avoid identifying with them. However, through shared experiences, many participants came to reframe social comparisons and see other participants as role models of effective coping. The group exercise context also provided a safe space to cope with anxiety through improving symptoms and cameraderie. For participants who held an identity as an athletic or active person, the fitness gained and opportunitites to help others strengthened or maintained that identity. These findings provide insight into the ways in which participants in a group exercise program for people with PD adapt to social and physical challenges in resilient ways, and offer suggestions for applied practice in exercise programs for this population.

An important contribution of this study is the experience participants had with shifting or reframing their social comparisons over the course of participation in the group exercise program from seeing people with more advanced symptoms as worse off (eliciting fear of future decline) to realizing that the people they were comparing to were adept at overcoming physical challenges despite often more advanced symptoms. For people with PD, social comparisons may tend to focus on people who are worse off symptomatically, as there is a high likelihood of experiencing similar declines in functioning in the future (Buunk et al., 1990). However, it is possible to use social comparisons in different ways and for different goals (Arigo et al., 2014). By shifting the point of comparison from symptom severity to exercise and coping abilities, participants developed hope that they, too, would be able to overcome similar challenges when their disease progressed, demonstrating considerable resilience. This reframing reflects a self-regulatory process of refocusing on controllable factors and letting go of uncontrollable factors that can alleviate the diminished perceived 
control that is often experienced in chronic illness (Frazier, Cotrell, \& Hooker, 2003). The reticence to participate due to fear of identifying with those with more advanced stages of the disease is similar to that documented in studies of group exercise for breast cancer survivors (McDonough, Sabiston, \& Ullrich-French, 2011), although it appeared to be more pervasive in the present study, perhaps due to the differences in illness trajectory between cancer and PD. From a practical perspective, it is important to note that the transition from experiencing anxiety about being around others with more advanced PD towards being inspired by their ability to cope appeared to occur as participants got to know each other better. It may be helpful to explore techniques for facilitating social bonds among members, such as matching new participants with mentors, to help speed and ease this transition for new members.

Anxiety, depression, and stress are commonly experienced among people with PD. The neurological degeneration of PD may directly cause depression (Jankovic, 2008), and being faced with disability and inevitable physical decline lead to considerable distress. Symptoms such as uncontrolled movement can be embarrassing and stigmatizing, and people with PD often try to conceal symptoms or retreat from public life (Bramley \& Eatough, 2005), which can result in social isolation and depression (Simpson, McMillan, \& Reeve, 2013). Group exercise provides several resources to help cope. Exercise is known to reduce anxiety via both physiological and psychological mechanisms (Stathopoulou, Powers, Berry, Smits, \& Otto, 2006). The symptom reduction induced by exercise (Alberts et al., 2011; Ridgel et al., 2012) could also relieve some stress. Furthermore, participants found the program to be free of stigma, inclusive and welcoming, and a safe space where they could display symptoms without fear of judgment. It was also a place where participants could build camaraderie through sharing jokes about PD that may have been taboo or awkward in other social settings. Humor can decrease anxiety (Crawford \& Caltabiano, 2011) and provide a way to reappraise the situation as less threatening (Bouskill, 2012). Coping through 
humor may foster solidarity and a shared social identity (Merz et al., 2009), and for those with an incurable illness, creative coping such as playing with taboo subjects through humor could involve rejecting and redefining stereotypes (Haslam et al., 2009). From an applied perspective, it is important for practitioners working with this population to be aware of these potential coping mechanisms. The humor may seem uncomfortable at first because of the transgression of taboos, but practitioners who are aware of its potential for reducing stress can be prepared to avoid displaying a negative reaction to or discouraging these interactions.

While it is possible for practitioners to see participants with a chronic illness like PD as frail or in need of help, it is important to consider these participants' capabilities, history, and identity, which can include an identity as an athlete or otherwise active person. Programs like this one may be particularly attractive for people with PD who have an athletic history, as it provides a direct means of maintaining and improving fitness and experiencing the fun and challenge of physical exertion. But providing opportunities for participants to help others with PD, both through informal interactions or through volunteering, coaching, or other formal roles may also provide alternate routes for bolstering athletic identity. Volunteering as an assistant for those at a more advanced stage of the disease may help the providers of such support reinforce their self-perceptions as physically capable and knowledgeable about physical activity, as well as provide direct assistance to the receiver, and model available support to the larger group who witnesses this behavior (McDonough et al., 2011). Altruism, the selfless concern for the well-being of others, and prosocial behavior are facilitated by perceived similarity and common fate (Vollhardt, 2009), and participants may find personal meaning through helping others with whom they identify. Altruism and providing support to others coping with the same illness has been identified as a coping strategy among others with chronic illnesses (Reeves, Merriam, \& Courtenay, 1999). 
Limitations of this study included the initial interviews being conducted by two researchers and the predominantly Caucasian and relatively high SES sample. Having a second researcher conduct some of the initial interviews was necessary due to practical constraints, but may have limited the first author's rapport with those participants in the follow-up interview and insights during analysis. The participants were all Caucasian, and most were of middle to high socioeconomic status. These characteristics were representative of the majority of the participants in the program from which they were sampled, but PD strikes people of diverse racial, ethnic, and socioeconomic backgrounds (Van Den Eeden et al., 2003) and future research is needed that considers how different cultural perspectives and available resources affect social and physical experiences within group exercise programs.

Future research is needed to examine the trajectories of change in social comparison as people with PD begin and continue a group exercise program, how humor and breaking taboos may act as a means for coping with PD and fostering social connections in such groups, and the best practices for structuring the group exercise environment to optimize physical and psychosocial benefits for those at varying stages of PD. Furthermore, while we have forwarded some potential practical implications, considerable work is needed to develop and evaluate the effectiveness of interventions for this population that may help relieve interpersonal anxieties and ease the transition into the group exercise environment, nurture creative coping strategies, and boster their identities as athletic and physically capable.

\section{Acknowledgements}

We would like to thank the staff from the exercise program for their help with recruiting participants, the program members who participated in this study, and

for conducting some of the interviews. 


\section{References}

Alberts, J. L., Linder, S. M., Penko, A. L., Lowe, M. J., \& Phillips, M. (2011). It is not about the bike, it is about the pedaling: Forced exercise and Parkinson's disease. Exercise and Sport Sciences Reviews, 39, 177-186. doi:10.1097/JES.0b013e31822cc71a

Arigo, D., Suls, J. M., \& Smyth, J. M. (2014). Social comparisons and chronic illness: Research synthesis and clinical implications. Health Psychology Review, 8, 154-214. doi:10.1080/17437199.2011.634572

Bouskill, K. (2012). Holistic humor: Coping with breast cancer. In D. H. Lende \& G. Downey (Eds.), The encultured brain: An introduction to neuroanthropology (pp. 213-235). Cambridge, Massachusetts: Massachusetts Institute of Technology.

Bramley, N., \& Eatough, V. (2005). The experience of living with Parkinson’s disease: An interpretative phenomenological analysis case study. Psychology and Health, 20, 223235. doi:10.1080/08870440412331296053

Bruner, M. W., Dunlop, W. L., \& Beauchamp, M. R. (2014). A social identity perspective on group processes in sport and exercise. In M. R. Beauchamp \& M. A. Eys (Eds.), Group dynamics in exercise and sport psychology (pp. 38-52). New York, NY: Routledge.

Buunk, B. P., Collins, R. L., Taylor, S. E., VanYperen, N. W., \& Dakof, G. A. (1990). The affective consequences of social comparison: Either direction has its ups and downs. Journal of Personality and Social Psychology, 59, 1238-1249. doi:00223514.59.6.1238

Charlton, G. S., \& Barrow, C. J. (2002). Coping and self-help group membership in Parkinson's disease: an exploratory qualitative study. Health \& Social Care in the Community, 10(6), 472-478. doi:10.1046/j.1365-2524.2002.00385.x 
Chrischilles, E. A., Rubenstein, L. M., Voelker, M. D., Wallace, R. B., \& Rodnitzky, R. L. (1998). The health burdens of Parkinson's disease. Movement Disorders, 13, 406-413. doi:10.1002/mds.870130306

Clare, L. (2002). We'll fight it as long as we can: Coping with the onset of Alzheimer's disease. Aging \& Mental Health, 6, 139-148. doi:10.1080/1360786022012682 6

Combs, S. A., Dyer Diehl, M. D., Chrzastowski, C., Didrick, N., McCoin, B., Mox, N., Staples, W. H., \& Wayman, J. (2013). Community-based group exercise for persons with Parkinson’s disease: A randomized controlled trial. Neurorehabilitation, 32, 117124. doi:10.3233/NRE-130828

Crawford, S. A., \& Caltabiano, N. J. (2011). Promoting emotional well-being through use of humor. Journal of Positive Psychology, 6, 237-252. doi:10.1080/17439760.2011.577087

Festinger, L. (1954). A theory of social comparison processes. Human Relations, 7, 117-140.

Frazier, L. D., Cotrell, V., \& Hooker, K. (2003). Possible selves and illness: A comparison of individuals with Parkinson’s disease, early-stage Alzheimer's disease, and healthy older adults. International Journal of Behavioral Development, 27, 1-11. doi: $10.1080 / 01650250143000526$

Hackney, M. E., \& Earhart, G. M. (2009). Health-related quality of life and alternative forms of exercise in Parkinson disease. Parkinsonism Related Disorders, 15, 644-648. doi: 10.1016/j.parkreldis.2009.03.003

Hackney, M. E., \& Earhart, G. M. (2010). Effects of dance on balance and gait in severe Parkinson disease: A case study. Disability and Rehabilitation, 32, 679-684. doi: $10.3109 / 09638280903247905$ 
Haslam, S. A., Jetten, J., Postmes, T., \& Haslam, C. (2009). Social identity, health and wellbeing: An emerging agenda for applied psychology. Applied Psychology: An International Review, 58, 1-23. doi: 10.1111/j.1464-0597.2008.00379.x

Heiberger, L., Maurer, C., Amtage, F., Mendez-Balbuena, I., Schulte-Monting, J., HeppReymond, M.-C., \& Kristeva, R. (2011). Impact of a weekly dance class on the functional mobility and on the quality of life of individuals with Parkinson's disease. Frontiers in Aging Neuroscience, 3, 1-15. doi:10.3389/fnagi.2011.00014

Jankovic, J. (2008). Parkinson’s disease: Clinical features and diagnosis. Journal of Neurology, Neurosurgery and Psychiatry, 79, 368-376. doi: 10.1136/jnnp.2007.131045

Kalia, L.V. \& Lang, A.E. (2015). Parkinson’s disease. Lancet, 386, 896-912.

Larkin, M., Watts, S., \& Clifton, W. (2006). Giving voice and making sense in interpretative phenomenological analysis. Qualitative Research in Psychology, 3, 102-120.

McDonough, M. H., Sabiston, C. M., \& Ullrich-French, S. (2011). The development of social relationships, social support, and posttraumatic growth in a dragon boating team for breast cancer survivors. Journal of Sport and Exercise Psychology, 33, 627-648.

Merz, E. L., Malcarne, V. L., Hansdottir, I., Furst, D. E., Clements, P. J., \& Weisman, M. H. (2009). A longitudinal analysis of humor coping and quality of life in systemic sclerosis. Psychology, Health \& Medicine, 14, 553-566. doi: $10.1080 / 13548500903111798$

O’Brien, M., Dodd, K. J., \& Bilney, B. (2008). A qualitative analysis of a progressive resistance exercise programme for people with Parkinson’s disease. Disability and Rehabilitation, 30, 1350-1357. doi:10.1080/09638280701614546 
Posen, J., Moore, O., Sadeh Tassa, D., Ginzburg, K., Drory, M., \& Giladi, N. (2001). Young women with PD: A group work experience. Social Work in Health Care, 32(1), 7791.

Reeves, P. M., Merriam, S. B., \& Courtenay, B. C. (1999). Adaptation to HIV infection: The development of coping strategies over time. Qualitative Health Research, 9, 344-361. doi: 10.1177/104973299129121901

Ridgel, A. L., Peacock, C. A., Fickes, E. J., \& Kim, C-H (2012). Active-assisted cycling improves tremor and bradykinesia in Parkinson's disease. Archives of Physical Medicine \& Rehabilitation, 93, 2049-2054. doi:10.1016/j.apmr.2012.05.015

Simpson, J., Haines, K., Lekwuwa, G., Wardle, J., \& Crawford, T. (2006). Social support and psychological outcome in people with Parkinson’s disease: Evidence for a specific pattern of associations. British Journal of Clinical Psychology, 45, 585-590. doi:10.1348/014466506X96490

Simpson, J., McMillan, H., \& Reeve, D. (2013). Reformulating psychological difficulties in people with Parkinson's disease: The potential of a social relational approach to disablism. Parkinson’s Disease, 2013, 1-8. doi:http://dx.doi.org/10.1155/2013/608562

Smith, J. A. (2004). Reflecting on the development of interpretative phenomenological analysis and its contribution to qualitative psychology. Qualitative Research in Psychology, 1, 39-54.

Smith, J. A., Flowers, P., \& Larkin, M. (2009). Interpretative phenomenological analysis: Theory, method, and research. London: Sage Publications Ltd.

Stathopoulou, G., Powers, M. B., Bery, A. C., Smits, J. A. J., \& Otto, M. W. (2006). Exercise interventions for mental health: A quantitative and qualitative review. Clinical Psychology: Science and Practice, 13(2), 179-193. 
Sunvisson, H. \& Ekman, S-L. (2001). Environmental influences on the experiences of people with Parkinson’s disease. Nursing Inquiry, 8, 41-50. doi:10.1046/j.14401800.2001.00089.x

Tajfel, H. \& Turner, J. C. (1979). An integrative theory of intergroup conflict. In W. G. Austin \& S. Worchel (Eds.), The social psychology of intergroup relations (pp. 33-47). Monterey, CA: Brooks/Cole.

Taylor, S. E., \& Lobel, M. (1989). Social comparison activity under threat: Downward evaluation and upward contacts. Psychological Review, 96, 569-575. doi:0033$295 X / 89 / \$ 00.75$

Van Den Eeden, S. K., Tanner, C. M., Bernstein, A. L., Fross, R. D., Leimpeter, A., Bloch, D. A., \& Nelson, L. M. (2003). Incidence of Parkinson’s disease: Variation by age, gender and race/ethnicity. American Journal of Epidemiology, 157, 1015-1022. doi: 10.1093/aje/kwg068

Vollhardt, J. R. (2009). Altruism born of suffering and prosocial behavior following adverse life events: A review and conceptualization. Social Justice Research, 22, 53-97. doi: 10.1007/s11211-009-0088-1 